Revista Destaques Acadêmicos, Lajeado, v. 9, n. 1, 2017. ISSN 2176-3070

DOI: http://dx.doi.org/10.22410/issn.2176-3070.v9i1a2017.1281

www.univates.br/revistas

\title{
PERSPECTIVAS PARA IMPLANTAÇÃO DE UMA ESTRUTURA DE CARREIRA EM UMA COOPERATIVA DE CRÉDITO
}

\author{
Leandra Bigliardi ${ }^{1}$, Liciane Diehl ${ }^{2}$
}

Resumo: A construção de um plano de carreira na organização onde exista um processo de gestão compartilhada, sendo o indivíduo protagonista da sua carreira e a empresa responsável pelo gerenciamento de oportunidades, é o caminho para o sucesso de ambos. O objetivo geral deste estudo é avaliar qual a melhor estrutura de plano de carreira para implementação em uma cooperativa de crédito. Para tanto, foi realizada uma pesquisa exploratória e descritiva, com abordagem qualitativa, cuja técnica de coleta de dados deu-se por benchmarketing e a análise dos dados ocorreu por análise interpretativa. Este trabalho contribuiu para demonstrar como é importante, para a valorização dos funcionários, possuir um plano de carreira na empresa. O estudo mostrou também que são poucas empresas que conseguem, efetivamente, aplicar de forma harmônica esse projeto, e que a estrutura mais observada é a Paralelas, mais conhecida como Y. Além das contribuições para a cooperativa, espera-se que este estudo seja um estímulo para que cada indivíduo pense na sua carreira profissional.

Palavras-chave: Carreira. Gestão de pessoas. Cooperativa.

\section{INTRODUÇÃO}

A chegada em massa da tecnologia alterou vários aspectos no mundo corporativo, não só na inovação em processos, informações, comunicação, mas também na abertura de várias oportunidades globais, de novos negócios, novas expectativas e, consequentemente, a necessidade de desenvolvimento de carreira, como cita Marques e Carli (2012).

Há alguns anos, a responsabilidade e o planejamento das carreiras era somente atribuída à organização e hoje esse cenário mudou, passando a ser

1 Pós-graduanda em Gestão Estratégica de Pessoas (UNIVATES). Graduada em Ciências Contábeis pela (UNIVATES). E-mail: lebigli@hotmail.com

2 Doutoranda em Psicologia (UNISINOS). Ma. em Psicologia Social (PUCRS). Esp. em Gestão Estratégica de Pessoas (UNIVATES). Psicóloga (UNISINOS). Professora da UNIVATES. E-mail: lici@univates.br 
obrigação do indivíduo também, conforme Dutra (2011). No entanto, para que o indivíduo consiga alinhar seus objetivos profissionais e pessoais, deve ter consciência das suas características e habilidades.

A prática do autoconhecimento é o diferencial, que o levará ao sucesso e o ajudará na busca por uma organização que internalize valores compatíveis com os seus. A base do pensamento do filósofo Sócrates já vinha ao encontro desta definição, pois é autor da expressão: "Conhece-te a ti mesmo". Quem não conhece a si mesmo, provavelmente não saberá para onde ir e desperdiçará energia, tempo e investimentos em busca de uma trajetória que talvez não seja condizente com suas habilidades.

Nesta ligação entre organizações e pessoas, o indivíduo deve pesar seus propósitos de concepções do mundo, crenças, desejos e suas preferências por determinada ocupação, carreira, empresa ou oportunidade (DUTRA, 2011; LUCENA, 2010). Os autores ressaltam que todos os indivíduos possuem talentos, os quais devem ser estimulados, bem como limitações que devem ser aperfeiçoadas.

Não é mais possível que apenas as empresas se preocupem com a carreira de cada funcionário, uma vez que as competências de cada indivíduo devem ser desenvolvidas de acordo com a sinalização do mercado e a aplicabilidade dessas competências poderá ser colocada em várias organizações. É importante que existam processos de gestão compartilhada de carreira, em que o indivíduo é protagonista da sua carreira e a empresa responsável pelo gerenciamento de oportunidades.

Pontes (2011) salienta que compete exclusivamente às pessoas, a decisão de qual trajetória de carreira deseja seguir, porém, cabe à organização a responsabilidade pela definição de um plano de carreiras que possa possibilitar o crescimento do indivíduo. Para Dutra (2011), a Administração de Carreiras é atualmente a resposta mais completa para as necessidades da empresa moderna na gestão de seus recursos humanos, que deve estimular o indivíduo a pensar na sua carreira profissional alinhada à pessoal.

Desta forma, esta pesquisa tem, como objetivo geral, avaliar qual a melhor estrutura de plano de carreira para implementação em uma cooperativa de crédito do interior do Rio Grande do Sul. A fim de atender esse objetivo, propõe-se: (i) analisar a atual composição dos cargos e organograma da empresa no sentido de obter um diagnóstico; (ii) investigar, na literatura, conceitos e tendências relacionadas ao plano de carreira nas organizações e; (iii) levantar informações junto a empresas do segmento de prestação de serviços que possuem planos de carreira estruturados e ativos. 


\section{REFERENCIAL TEÓRICO}

\subsection{A cooperativa de crédito}

A jovem cooperativa, atualmente com 20 anos, tem sua sede (Unidade Administrativa) localizada na cidade de Lajeado-RS, e possui oito Unidades de Negócios distribuídas estrategicamente pela sua área de ação nas cidades de Lajeado, Estrela, Venâncio Aires, Santa Cruz do Sul, São Jerônimo, Carazinho, Passo Fundo e Soledade, todas no Rio Grande do Sul. A cooperativa atualmente conta com 55 funcionários, que estão distribuídos entre 15 tipos de funções e atende cerca de 3.500 cooperados.

A estrutura organizacional da cooperativa divide-se nos níveis: Estratégico, Tático e Operacional. O nível Estratégico é onde as decisões são tomadas com a definição de quando e porque serão realizadas e é composto pelos Diretores e Conselho de Administração da cooperativa, bem como o Gerente Geral, o de Negócios e o Administrativo Financeiro. O tático compõe a forma organizacional de forma intermediária e cabe a este nível decidir como serão feitas as atividades, onde estão alocados os Gerentes de Unidade de Negócios, os Coordenadores de Unidade de Negócios e o Coordenador de Comunicação. Já o nível operacional tem a responsabilidade de executar as tarefas para atingir os objetivos da forma que foi estabelecida previamente. Atualmente a cooperativa conta com nove funções neste nível.

Em 2012, houve a incorporação de outra cooperativa de crédito trazendo novos desafios e mudanças, entre elas, a necessidade de reestruturar e profissionalizar a equipe. Diante desse cenário, uma das primeiras ações foi realizar o mapeamento das funções desenvolvidas pelos funcionários, pois se identificava a necessidade de segregação das mesmas (BUTTENBENDER; HEINEN, 2016). Após esse levantamento, realizou-se a descrição de cada cargo existente no organograma da cooperativa. Testes de perfis e entrevistas individuais auxiliaram na organização e reestruturação dos cargos e funções, para uma maior organização das atividades e demandas que a cooperativa necessitava.

Atualmente, todas as vagas que surgem, na cooperativa, primeiramente são oferecidas ao público interno e, caso não seja encontrado o perfil adequado, disponibiliza-se externamente. Com a agressividade do mercado financeiro perante a crise instalada no país em 2016, sente-se a necessidade de buscar profissionais cada vez mais capacitados. Estes profissionais procuram muito além de bom salário: buscam qualidade de vida, perspectiva de crescimento, realização profissional e, consequentemente, empresas que pensem em planejamento de carreiras.

No início de 2016, a cooperativa implantou o plano de cargos e salários com o intuito de manter o equilíbrio entre a remuneração praticada no mercado e a exercida internamente, buscando satisfazer as necessidades dos funcionários, 
com remuneração justa e compatível com a situação econômica da cooperativa. Nessa fase, também as competências do grupo tático da cooperativa começaram a ser traçadas e avaliadas.

Com esse mesmo grupo, em outubro de 2016 foram realizadas entrevistas de Programa de Desenvolvimento Individual (PDI), que servirá para monitorar o desenvolvimento das competências desses profissionais entre os ciclos de avaliação. Nesse caso, o PDI funciona como um plano de evolução que indica o caminho para que o funcionário suba cada novo degrau na escalada de carreira e servirá de apoio quando ocorrer a implantação do Plano de Carreira na cooperativa. O PDI é um pilar fundamental para o sistema de liderança, pois auxilia no fortalecimento do potencial de cada talento de maneira plena, desenvolvendo os pontos fracos e potencializando os pontos fortes, como reforçam Marques e Carli (2012). Nesse projeto, as competências avaliadas foram: Liderança, Comunicação e Influência; Trabalho em Equipe e Cooperação; Relacionamento; Foco no Resultado; Flexibilidade; Conhecimentos Técnicos; Credibilidade; Capacidade de Negociação e Inovação; e Criatividade e Comprometimento.

Com objetivo de ser mais atrativa no mercado de trabalho, reter seus talentos, desenvolvê-los e, assim, contribuir para a autorrealização dos trabalhadores e consequente melhorias nos seus resultados, a cooperativa sente a necessidade de implantar um sistema de plano de carreira, que também foi um dos itens apontados na última Pesquisa de Clima Organizacional.

Define-se carreira, conforme London e Stumph (1982) citado por Dutra (2011, p. 17):

Carreira são as sequências de posições ocupadas e de trabalhos realizados durante a vida de uma pessoa. A carreira envolve uma série de estágios e a ocorrência de transições que refletem necessidades, motivos e aspirações individuais e expectativas e imposições da organização e da sociedade. Da perspectiva do indivíduo, engloba o entendimento e a avaliação de sua experiência profissional, enquanto, da perspectiva da organização, engloba políticas, procedimentos e decisões ligadas a espaços ocupacionais, níveis organizacionais, compensação e movimento de pessoas. Estas perspectivas são conciliadas pela carreira dentro de um contexto de constante ajuste, desenvolvimento e mudança.

Já plano de carreira, Oliveira (2013, p. 5) descreve da seguinte forma:

Plano de carreira é a explicação formal de um conjunto planejado, estruturado, sustentado e sequencial de estágios que consolidam a realidade evolutiva de cada indivíduo, de forma interativa com as necessidades das em empresas e das comunidades onde elas atuam. 
O autor também sustenta que, seguramente, a principal finalidade de um plano de carreira é dar foco de direcionamento profissional para as pessoas.

Desta forma, relaciona-se a seguir o papel das pessoas, dos líderes e da organização neste processo de busca pela carreira profissional ideal do indivíduo.

\subsection{O papel das pessoas}

No momento da opção pela carreira, muitos indivíduos apenas observam o ambiente da empresa que estão inseridos, porém, o primeiro passo a ser dado é olhar para dentro de si mesmo, a fim de identificar o que gosta, o que o estimula, o que o satisfaz, o que o motiva. Assim, estarão de fato sendo mais assertivos, já que vários fatores influenciam, a todo momento, o profissional em relação à escolha da carreira, tais como: expectativas, necessidades econômicas, de realização, entre outros (DUTRA, 2011).

De acordo com Chiavenato (2002, p. 113), o indivíduo possui motivações, dispostas na hierarquia das necessidades de Maslow, teoria da motivação apresentada por Abraham Maslow, em que as necessidades do indivíduo de nível mais baixo (primárias) devem ser satisfeitas antes das necessidades de nível mais alto, chamadas de secundárias. Segundo o autor, não são todas as pessoas que conseguem chegar ao topo da pirâmide, onde está alocada a necessidade de autorrealização, de autodesenvolvimento, onde a pessoa consegue usar todo o seu potencial.

Muitas pessoas almejam o sucesso, mas esquecem que ele não surge por acaso e tampouco como em um passe de mágica. É preciso que a pessoa trace estratégias para desenvolver competências que a farão se destacar e tenha objetivos que sirvam de estímulo para novas conquistas, sempre seguindo o caminho coerente entre suas experiências e aprendizados e suas expectativas reais de futuro (OLIVEIRA, 2013).

London e Stumph (1982), citados por Dutra (2011), apresentam três tarefas que devem ser realizadas sistematicamente pelo indivíduo: autoavaliação (suas habilidades e potenciais), estabelecimento de objetivos de carreira (plano baseado na autoavaliação e nas oportunidades que a empresa oferece) e implementação do plano de carreira (capacitação e experiências necessárias para competir e atingir o perfil ideal para a oportunidade). $\mathrm{O}$ autor sugere também agrupar as categorias das teorias de escolha da carreira em: compatibilidade e processo de escolha. A primeira afirma que determinadas pessoas escolhem suas ocupaçoes baseadas na compatibilidade entre $o$ indivíduo e a ocupação escolhida. Já o processo de escolha se dá ao longo da trajetória de vida do indivíduo até chegar à escolha da ocupação, sendo ela dentro da organização ou fora dela.

Maxwell (2011) afirma que as pessoas devem seguir suas paixões, e esse é o segredo para alcançar o seu potencial, que ninguém consegue chegar ao 
melhor desempenho sem perseguir sua paixão. Os indivíduos precisam agir mais proativamente, em busca de crescimento pessoal e profissional, focando a sua felicidade. Queiroz e Leite (2011) afirmam que é preciso que o indivíduo goste do seu trabalho ou que veja uma razão para realizá-lo, para conseguir produzir com qualidade, criatividade, gerando prazer e realização interna.

\subsection{Responsabilidade dos líderes e da organização}

Pontes (2011) menciona que a organização precisa desenvolver um sistema de Administração de Carreiras que sirva de suporte para as pessoas planejarem suas carreiras, conciliando o desenvolvimento das pessoas com os objetivos da empresa. Definir a formatação e características das estruturas de carreira, níveis dentro de cada estrutura, bem como requisitos de acesso e os instrumentos de gestão, também são de encargo da organização. Outro papel importante da empresa é definir a metodologia de implementação e atualização do sistema, levando-se em conta a cultura, o momento histórico e as necessidades da instituição.

O mesmo autor enfatiza que é de responsabilidade da empresa ofertar às pessoas ferramentas de apoio para o desenvolvimento, com instrumentos de autoconhecimento, relatando sobre os tipos de responsabilidades e recompensas das oportunidades internas e do mercado de trabalho.

As organizações precisam assumir responsabilidades com foco no comprometimento, nas pessoas, no conhecimento, nas competências e nas entregas de cada indivíduo. Nesse contexto, Pontes (2011) aponta que os programas de recursos humanos devem constituir condições facilitadoras para que a organização atinja níveis mais elevados de qualidade e produtividade. Nesse ponto, Pontes (2011) e Lucena (2010) reafirmam a importância da geração de oportunidades de crescimento profissional, por meio de um plano estruturado de carreira e do clima organizacional positivo, decorrente dos estilos de gestão. Araújo e Garcia (2010) enfatizam que as empresas precisam ter algumas regras claras que facilitem a elaboração de um plano de carreira e norteiem os funcionários, tais como: as entregas e as competências esperadas do indivíduo, a qualificação, o perfil necessário e a estruturação e divulgação do sistema de oportunidades ofertado pela empresa.

Para Marques e Carli (2012), a empresa, através da área de Gestão de Pessoas, deverá atuar de maneira criativa na composição do mapa de carreiras, construindo trilhos paralelos à estrutura de plano de carreira a ser escolhido pela organização. Para a implantação, precisará listar as competências (conhecimento, habilidade e atitude) necessárias para cada cargo ou função e encontrar formas diferentes de deslocamento profissional, sempre obedecendo aos critérios de cada função. Os autores recomendam também a prática Job Rotation, que amplia a capacidade técnica e que vai além do seu trilho específico de carreira, mesmo que seja de maneira descomprometida. Queiroz e Leite 
(2011, p. 59) reforçam esta prática referindo que a mesma "contribui para um espírito de colaboração, potencializando e desenvolvendo a competência de visão sistêmica nos funcionários e preparando-os para ocupar várias posições dentro da empresa, o que eleva sua empregabilidade e capacidade produtiva".

A preparação dos líderes é outro ponto importantíssimo, pois, além de se conhecer e inspirar os funcionários, também necessita-se conhecer sua equipe para, então, conseguir orientá-los, estimulando-os a adquirir competências e a potencializá-las para que cada um encontre seu caminho. E é neste ponto que entra a ferramenta de feedback, que é essencial na gestão da carreira do trabalhador, pois ela oportuniza a motivação e a velocidade que o profissional pode atingir, tanto os objetivos individuais, quanto os da organização (QUEIROZ; LEITE, 2011).

Segundo dados da Great Place to Work, Queiroz e Leite (2011) argumentam que confiança é um fator determinante nas relações organizacionais. Os autores afirmam que, existindo respeito e confiança entre líder e liderado, nasce uma relação de apreço e admiração e que os líderes devem muito mais do que apontar o caminho, devem ser 'modelo', inspiração para as pessoas que os cercam, auxiliando-os no alcance dos seus objetivos de carreira.

\subsection{Estruturas de carreira}

Segundo Dutra (2011), estrutura de carreira é o desenho da trajetória que o funcionário percorrerá dentro da empresa e irá norteá-lo rumo ao objetivo desejado, juntamente com as demais regras de ascensão. Este desenho é influenciado por diversos aspectos, como: valores, características, momento da organização, estratégias de negócios e pessoas e particularidades da categoria profissional abrangida pela carreira.

Pontes (2011) refere que, com essas estruturas, podemos construí-las através da hierarquização preestabelecida de cargos. Neste caso, o funcionário fica atrelado à disponibilidade de vagas daquele determinado cargo e a valorização da pessoa ocorre apenas em função do cargo. Porém, se a estrutura for construída em segmentos de carreiras, o cargo é mero coautor e o que vai definir o crescimento do indivíduo é o conjunto de suas capacidades. Araújo e Garcia (2010) reforçam que a empresa poderá estruturar várias formas de carreiras, já que não existe definição restrita e cada empresa pode adaptar ao seu jeito de ser.

As estruturas de carreiras básicas e citadas por Dutra (2011) podem apresentar diversas formas em função das perspectivas mencionadas acima, porém apresentam três tipos básicos de desenho: estruturas em Linha, estruturas em Rede e estruturas Paralelas.

As estruturas em Linha caracterizam-se por apresentar uma sequência de posições, alinhadas em uma única direção, verticalmente, e não oferece outras opções aos funcionários. Quando centralizado no trabalho, cada 
estágio da carreira será caracterizado por um conjunto de responsabilidades e atribuições, já se estiver centralizado na pessoa, será diferenciado por um conjunto de atributos do indivíduo.

As estruturas em Rede possuem mais opções de escolha às pessoas, permitindo-as vislumbrar sua trajetória com base nos critérios previamente estabelecidos pela empresa. Esta estrutura apresenta uma aparente opção de escolha, em virtude de o caminho de ascensão ser desenhado pela empresa, não oferecendo à pessoa condições de interferência nesta trilha (ARAÚJO; GARCIA, 2010; DUTRA, 2011).

Por outro lado, as estruturas Paralelas são mais abrangentes e flexíveis para operacionalizar a administração de carreiras e, na prática, consistem no posicionamento de duas estruturas em linha, uma com braço técnico e outro de gerencial de forma paralela, oferecendo maior número de alternativas de migração, já que não seguem a linha fixa do organograma. Esta estrutura apresenta três formatos: $\mathrm{Y}$ (formato de um Y), múltiplas (várias linhas verticais) e totalmente paralelas (duas linhas verticais, uma ao lado da outra).

A forma "Y" é a mais conhecida e utilizada pelas empresas, identificam Araújo e Garcia (2010). Sua base é sustentada pela carreira tecnológica e é única para todos, a partir daí o caminho a ser escolhido pode ser no segmento técnico ou gerencial conforme habilidades e oportunidades.

Dutra (2011) argumenta que a forma múltipla vem evoluindo e permite o crescimento por eixos profissionais, além dos que existem na carreira " $Y$ ", ainda podem seguir trajetórias em todos os segmentos oferecidos pela organização e todos com crescimento até o nível gerencial.

Já a forma totalmente paralela, a menos usual, oferece apenas dois grupos, cada qual com sua própria administração e recursos. Um dos grupos é encarregado da função operacional, enquanto que o outro grupo se preocupa com a função administrativa.

\section{MÉTODO DA PESQUISA}

Este estudo se desenvolve por meio de pesquisa exploratória e descritiva com abordagem qualitativa. Oliveira (1999) afirma que a pesquisa qualitativa consegue transcrever situações complexas ou particulares e estimula a leitura sobre o assunto da pesquisa descrevendo, relatando minunciosamente o que os diferentes autores escrevem sobre o assunto.

O mesmo autor sustenta que pesquisa exploratória tem como objetivo a formulação de um problema para elaboração de hipóteses e possibilita obter maiores informações acerca de um determinado produto. Gil (2010) enfatiza que pesquisa exploratória tem como objetivo proporcionar uma visão geral de determinado fato por comparação. Já o estudo descritivo, segundo Oliveira (1999), engloba aspectos gerais e amplos de um fenômeno social e proporciona uma análise mais detalhada acerca dele. 
Para a obtenção das informações, a técnica de coleta de dados utilizada foi o benchmarketing que, segundo Araújo (2012), nada mais é do que aprender com a prática dos outros, do que está acontecendo no mercado, levando em conta seus acertos e que nos leva a ter maior assertividade na implantação de projetos que ainda não temos expertise suficiente. A análise dos dados, por sua vez, ocorreu por análise interpretativa. De acordo com Gomes (2015), a interpretação é um procedimento que procura ir além do material, sendo que se discutem os resultados da pesquisa numa perspectiva mais ampla, trabalhando na produção do conhecimento de uma área disciplinar ou de um campo de atuação.

Cinco empresas que possuem diretrizes, estruturas de carreira e instrumentos de gestão formando um Sistema de Administração de Carreiras efetivo foram contatadas e convidadas a participar do estudo. As organizações foram eleitas por motivo de proximidade e conveniência. Das cinco organizações, apenas três se disponibilizaram a responder o questionário, as quais serão chamadas de Alfa, Beta e Gama. As respondentes estão localizadas no estado do Rio Grande do Sul, Alfa e Beta pertencem à cidade de Lajeado e Gama está situada em Porto Alegre. Todas possuem atividade no segmento de prestação de serviços. A empresa Alfa possui 70 funcionários, a empresa Beta 1.100 funcionários e a empresa Gama, 1.000 funcionários.

A pesquisadora enviou, através de e-mail, um link com o questionário para que as três empresas pudessem respondê-lo, com prazo estipulado para devolução. O questionário, composto por seis questões, apresentava cinco perguntas abertas que tratavam do tempo para implantação, como ocorreu a escolha pela estrutura e relatos sobre o envolvimento das lideranças, facilidades e dificuldades encontradas na implantação. A outra pergunta era fechada e oferecia opções de escolha para que os entrevistados pudessem escolher uma única alternativa.

\section{APRESENTAÇÃO E ANÁLISE DOS RESULTADOS}

Após o recebimento das respostas, realizou-se a interpretação a partir de seis categorias criadas conforme questões da pesquisa:

\subsection{Estrutura de plano de carreira adotada pelas empresas}

Nesta questão, as empresas deveriam optar por uma das opções: ESTRUTURA EM LINHA, em que a sequência de posições está alinhada em uma única direção; ESTRUTURA EM REDE, que oferece várias opções para cada posição na empresa e ESTRUTURA PARALELAS, onde as pessoas orientam suas trajetórias profissionais em duas direções: natureza profissional e natureza gerencial. As três empresas (Alfa, Beta e Gama) responderam que a estrutura implementada é a ESTRUTURA PARALELAS. 


\subsection{A escolha pela estrutura de carreira}

No que se refere a como se deu a escolha pela estrutura de carreira, a empresa Alfa respondeu que, após a direção analisar as opções disponíveis, identificou-se que a estrutura paralela $(\mathrm{Y})$ seria possível ser implantada na empresa e seria vantajoso tanto para organização, quanto para os funcionários. Já para a empresa Beta, a estrutura paralela $(\mathrm{Y})$ foi pensada por contemplar o crescimento dos cargos não só na área de gestão, mas também na linha técnica. A empresa Gama respondeu que optou pela estrutura paralelas (Y) e que foi atrelada à avaliação de desempenho.

\subsection{Facilidades encontradas na implantação}

As facilidades encontradas na implantação do plano de carreira foram relatadas da seguinte forma: a empresa Alfa citou o fato de serem as mesmas pessoas que realizaram a análise e responsáveis pela execução do projeto de implantação do plano de carreira. Para a empresa Beta, a facilidade mencionada foi a abertura para discussão com gestores, enquadramento de boa parte dos cargos na nova estrutura e adequação da remuneração com a prática no mercado. Já a empresa Gama afirmou que a facilidade foi a aderência dos funcionários para implantação do projeto.

\subsection{Dificuldades encontradas na implantação}

A empresa Alfa apontou como dificuldade o entendimento e a forma de divulgação aos funcionários. A empresa Beta aludiu como dificuldade o enquadramento de alguns cargos, principalmente os mais antigos na nova estrutura e conscientização de que nem todos teriam aumento de salário. E para a empresa Gama, a dificuldade foi colocar o projeto em prática.

\subsection{Tempo entre o planejamento e a implantação do plano de carreira}

A empresa Alfa informou que foram dois anos entre o planejamento e a implantação do projeto, a empresa Beta afirmou que foi cerca de um ano e meio e a empresa Gama levou um ano.

\subsection{Envolvimento das lideranças}

No que se refere ao envolvimento das lideranças no processo de implantação do plano de carreira, a empresa Alfa citou que o projeto foi implantado primeiramente pela Direção para ter maior envolvimento e comprometimento. A empresa Beta respondeu que, no início do projeto, todos gestores foram envolvidos e, quando a área de recursos humanos teve uma prévia da estrutura pronta, também foi apresentado o modelo para a equipe de gestores para opiniões, sugestões e críticas. Após o trabalho concluído, todos os gerentes foram sensibilizados para apresentar a estrutura final do projeto as 
suas equipes. Já a empresa Gama apontou que o envolvimento das lideranças foi estratégico, sempre atrelado ao item de satisfação das metas dos executivos.

A partir do contato inicial com as empresas para questionar se elas tinham ou não implantado o plano de carreira, foi possível identificar que são poucas as empresas que atualmente implementam um projeto de plano de carreira. Essa constatação converge com a conclusão da primeira pesquisa realizada pela Consultoria Global de Benchmarking (CEB), sobre as práticas de recursos humanos da América Latina e divulgada pela Revista Você RH no mês de dezembro/2016. O resultado mostra que somente $20 \%$ das empresas latinas desenham rotas profissionais claras e apenas quatro em dez permitem que os indivíduos sigam suas próprias aspirações. Essa falta de oportunidade segue como sendo o principal motivo de saída dos funcionários e quase $70 \%$ das pessoas estão desgostosas com a visão futura de carreira.

É perceptível que as empresas que procuram trilhar um caminho sustentável, evitando turnover, captando e mantendo talentos e preocupadas com a valorização dos profissionais são as que procuram desenhar e implantar com regras claras um plano de carreira. Tais empresas acreditam que pessoas realizadas passam essa energia adiante e isso se multiplica como algo contagioso, refletindo na produtividade.

Conforme dados do presente estudo, o plano de carreira pode ser implantado tanto em empresas que possuem um número maior de funcionários, quanto em empresas menores, inclusive com aplicação da mesma estrutura de plano de carreira e que as dificuldades serão amenizadas se a direção e líderes forem envolvidos diretamente.

Nota-se, também, que para o sucesso do projeto, é imprescindível que os funcionários entendam perfeitamente o funcionamento do plano de carreira, que exista comunicação eficiente entre empresa, lideranças e profissionais para que as expectativas sejam alinhadas. Através das respostas é possível identificar também, que o processo de conscientização por parte de todos os envolvidos antes da implantação é de suma importância.

\section{CONSIDERAÇÕES FINAIS}

Após a realização da pesquisa com estas três empresas, pode-se afirmar que, para o organograma atual da cooperativa, a estrutura mais adequada é a Paralelas, por ser mais abrangente e flexível, assim como citado por Dutra (2011). Araújo e Garcia (2010) afirmam que a Estrutura Paralela mais usada é a Y, da mesma forma confirmada pelos entrevistados.

Este trabalho contribuiu para demonstrar como é importante, para a valorização dos trabalhadores, possuir um plano de carreira na empresa. São poucas as empresas que, efetivamente, conseguem aplicar, de forma harmônica esse projeto. E que a estrutura a ser implantada deve ser aquela que agrade empresa e trabalhador e que nos casos estudados é a estrutura Paralelas, mais 
conhecida como Y. Além disso, serve de estímulo para que cada profissional pense na sua carreira, primeiramente se realmente possui autoconhecimento, se sabe onde quer chegar e o que está fazendo para chegar ao ponto desejado.

Outra contribuição importante deste trabalho é dirigida aos líderes, pois têm o papel relevante de facilitador e parceiro que eles têm na carreira das suas equipes, talvez maior que a própria empresa, pois são eles que estão diária e diretamente acompanhando os funcionários. São eles quem devem, de certo modo, apontar o caminho, que como cita Queiroz e Leite (2011) é mais do que dizer o que fazer, é servir de inspiração, é ser um exemplo a ser seguido.

Para a cooperativa fica a contribuição de que plano de carreira é a base de relacionamento entre organização e funcionário, sendo ponto de conciliação entre ambos.

\section{REFERÊNCIAS}

ARAÚJO, Luis C. G. de; GARCIA, Adriana A. Gestão de Pessoas. São Paulo: Atlas, 2010.

ARAÚJO, Luis C. G. de. Organização, sistemas e métodos e as tecnologias da gestão organizacional. São Paulo: Atlas, 2012.

BÜTTENBENDER, Roselaine; HEINEN, Bruna Araújo. 20 Anos de História e Cooperação Unicred VTRPP. Porto Alegre: Sescoop, RS, 2016.

CARLI, Edson; MARQUES, Jose Roberto. Coaching de Carreira Construindo Profissionais de Sucesso. São Paulo: Ser Mais, 2012.

CHIAVENATO, Idalberto. Teoria Geral da Administração. Rio de Janeiro: Campus, v. 2, 2002.

DUTRA, J. S. Administração de carreira: uma proposta para repensar a gestão de pessoas. São Paulo: Atlas, 2011.

GIL, Antônio Carlos. Como elaborar projetos de pesquisa. 5. ed. São Paulo: Atlas, 2010.

GOMES, Romeu. Análise e Interpretação de dados de pesquisa qualitativa. In: MINAYO, Maria Cecília de Souza (Org.). Pesquisa Social: Teoria, método e criatividade. 34. ed. Petrópolis, RJ: Vozes, 2015, p. 79-108.

LUCENA, Maria Diva da Salete. Planejamento de Recursos Humanos. São Paulo: Atlas, 2010.

MAXWELL, John C. O livro de ouro da liderança: o maior treinador de líderes da atualidade apresenta as grandes lições de liderança que aprendeu na vida. 2. ed. Rio de Janeiro: Thomas Nelson Brasil, 2011. 
OLIVEIRA, Djalma de Pinho Rebouças de. Plano de carreira foco no indivíduo:

Como elaborar e aplicar para ser um profissional de sucesso. São Paulo: Atlas, 2013.

OLIVEIRA, Silvio Luiz de. Tratado de Metodologia científica: projetos de pesquisa, TGI, TCC, monografias, dissertações e teses. São Paulo: Pioneira Thomsom Learning, 1999.

PONTES, Benedito Rodrigues. Administração de Cargos e Salários - Carreira e Remuneração. São Paulo: LTR, 2011.

QUEIROZ, Cláudia; LEITE, Christiane. O ELO da Gestão de carreira: o papel do empregado, da liderança e da organização. São Paulo: DVS Editora, 2011.

REVISTA VOCÊ RH. 47. ed. [S.1.]: Editora Abril, dez. 2016/jan. 2017. 